\title{
Occupational Risk Assessment Using Spherical Fuzzy Safety and Critical Effect Analysis for Shipyards
}

\author{
(1) Fatma Kutlu Gündoğdu1, (1) Seyed Amin Seyfi-Shishavan² \\ ${ }^{1}$ National Defence University, Turkish Air Force Academy, Department of Industrial Engineering, İstanbul, Turkey \\ ${ }^{2}$ İstanbul Technical University, Department of Industrial Engineering, İstanbul, Turkey
}

\begin{abstract}
Today, occupational health and safety is a prominent issue in all branches of the industry. In Turkey, shipyards are highly prone to accidents related to occupational safety. Clearly defining hazard risks and taking precautions against identified priority risks are essential in preventing these risks. This study proposes a two-stage risk-assessment method based on spherical fuzzy sets (SFSs), which is a new fuzzy set theory. A systematic risk-assessment tool with the SFSs was developed combining two of the most reliable decision-making methods: "Analytical hierarchy process (AHP)" and "VlseKriterijumska Optimizacija I Kompromisno Resenje (VIKOR)." The proposed method was applied in a real case study considering the shipyards in Turkey. Results showed that the developed two-stage risk-assessment approach provides reasonable results in identifying high-risk hazards to ensure occupational safety in a shipyard. A sensitivity analysis was conducted to show the reliability and validity of the results.
\end{abstract}

Keywords

Shipyard accidents, Risk assessment, Spherical fuzzy safety and critical effect analysis, AHP, VIKOR

\section{Introduction}

In the recent competitive world, shipyards have to check their production processes to decrease breakdowns and retain their competitive power. Injuries, death, and work loss can be the results of failures. Thus, shipyards must identify and reduce risks in their production system. To perform this procedure, a wide-ranging process analysis must be performed, and reasons for failures must be identified [1]. In addition to safety and health, occupational injuries can also impact economies due to high costs related to work injuries [2]. Taking into account the importance of the abovementioned issues, the concept of occupational health and safety (OHS) can be considered. OHS can be defined as the investigation and identification of hazard risks that may harm employees' health and taking precautions to control these hazard risks [3]. In other words, OHS comprises methodical studies to protect workers from hazardous conditions and circumstances that might be caused by diverse reasons while performing a job in a working environment [4].

One of the key roles in the field of OHS is risk assessment (RA). Indeed, the desired occupation's risk analysis has fundamental and crucial importance in the OHS studies. RA is recognized as the procedure of classifying, assessing, and ranking risks in organizational assets and operations [5]. In another definition by Rausand and Haugen [6], the differences between risk analysis and risk evaluation are explained. Risk analysis is the methodical employment of on-hand information to find out hazards whereas risk evaluation contains decisions on the acceptability of the risk in terms of some important criteria. The entire procedure of risk analysis and risk evaluation is termed RA. RA identifies reasons for risks and suggests control measures to put into action before an injury occurs [7]. An RA procedure comprises the following steps $[8,9]$ :

1. Identify hazards: To identify all hazards and situations that could cause any harm or loss.

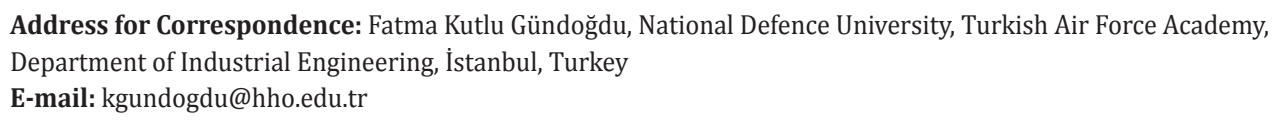

Received: 07.12.2020 Accepted: 17.04 .2021 \footnotetext{
ORCID ID: orcid.org/0000-0001-6746-6014

To cite this article: F. Kutlu Gündoğdu and S.A.S. Shishavan, "Occupational Risk Assessment Using Spherical Fuzzy Safety and Critical Effect Analysis for Shipyards." Journal of ETA Maritime Science, vol. 9(2), pp. 110-119, 2021.

${ }^{0}$ Copyright 2021 by the Journal of ETA Maritime Science published by UCTEA Chamber of Marine Engineers 
2. Decide who might be harmed and how: To determine who and how one might be harmed in each hazard.

3. Decide on precautions based on risk evaluation: To examine the degree of risk that may arise from undesirable events.

4. Record findings and implement them: To implement the results of RA into training.

5. Observe the RA and update if necessary: To review what you do and on go basis. The process may go differently than planned. Thus, we should observe the results and update them if necessary.

Various risk-assessment techniques are present in the literature with their definite characteristics and outcomes. The most used risk-assessment methods are given below with short definitions [10]:

- Hazard and operability study: It can be defined as the systematic identification of hazards in a process plant design.

- Fault tree analysis: It is a potentially quantitative risk analysis method to analyze contributors' details to the main annoying events.

- Event tree analysis: To potentially use quantitative methods to analyze the details of the development of major unwanted events.

- What-if analysis: What-if questions are asked about what could go wrong and what would happen if things go wrong.

- Failure mode and effect analysis (FMEA): It is used to recognize potential failures and discover effects that the failures would inflict.

An industry has to be familiar with some important definitions before implementing one of the risk-assessment methods.

1. Acceptable risk level: The risk level that does not cause damage to human resources or work equipment.

2. Risk: The possibility of failure, injury, or any other destructive result caused by danger or hazard.

3. Hazard: A situation with the potential to lead to injury in the human body and/or damage to the business.

The Fine-Kinney method is a traditional OHS riskassessment method that yields risk scores and obtain each hazard's risk classes [11]. This method was introduced by Kinney and Wiruth [12] and is a comprehensive and quantitative approach to support managers in evaluating and controlling hazard risks. This method is utilized to determine the ranking of the accomplishment of measures and resource employment according to the ranking of risks. Many researchers in various fields have employed this method. Ilbahar et al. [4] developed a new integrated method, including the Fine-Kinney, Pythagorean analytical hierarchy process (AHP), and a fuzzy inference system for the RA in the field of OHS. Oturakçı et al. [13] developed a new methodology for the Fine-Kinney method used in the construction industry. The integration of the fuzzy AHP (FAHP), fuzzy VlseKriterijumska Optimizacija I Kompromisno Resenje (VIKOR) (FVIKOR), and FineKinney methods was proposed by [14] to control the ballast tank maintenance. In another research, Kokangül et al. [14] combined the AHP method to find hazards and the Fine-Kinney method's priorities to assess a production company's hazard risks. Wang et al. [15] introduced a fuzzy Fine-Kinney framework in which the extended MULTIMOORA method is developed to appraise the risk of ballast tank maintenance. Gul and Celik [16] analyzed the risks of transportation systems by proposing a hybrid Fine-Kinney method. A new FineKinney-based risk-assessment framework integrating the FAHP and FVIKOR approaches was proposed by [17]. Moreover, Yllmaz and Ozcan [18] proposed a risk evaluation and ranking application integrated with the AHP and Fine-Kinney methods to get risk values for lifting vehicles used in building sites. Karasan et al. [19] developed a novel approach and its extension with the Pythagorean fuzzy sets by incorporating the FMEA and Fine-Kinney parameters to provide a comprehensive and accurate RA. Gul et al. [20] presented a novel fuzzybased method utilizing the FAHP and FVIKOR methods to find the parameters' weights and priorities of hazards in the Fine-Kinney risk-assessment approach for the construction of wind tribunes. In a comprehensive study, Gul et al. [21] investigated the Fine-Kinney method and its fuzzy extensions, approaches, case studies, and Python applications. Gul et al. [22] proposed a Fine-Kinney based occupational RA integrating fuzzy best-worst method and fuzzy multi-attribute ideal real comparative analysis. In another research, Gul et al. [23] extended the Fine-Kinney method to interval type-2 fuzzy sets and the QUALIFLEX method.

Since the industrial revolution and globalization, shipyards and the shipbuilding industry hold a significant trading role [24]. In the last decade, with expansions in the global market, the Turkish shipbuilding industry experienced an increment in shipbuilding and export capacity [25]. Owing to the types of equipment and intricacy of manufacturing processes, the shipbuilding industry is categorized as a heavy industry. Therefore, shipyards must inspect their production processes to reduce failures [1]. As mentioned before, failures cause injury, death, and work loss, which results in the loss of money. For these reasons, shipyards must recognize 
and reduce risks as much as possible. To realize this, a comprehensive process analysis of the current situation must be performed and reasons for failures must be identified. The variety and harshness of work-related accidents experienced in the shipyards in Turkey have increased over years. Hundreds of serious injuries and even deaths have occurred because of these accidents [26]. The number of occupational fatalities in the Turkish shipyards between 2000 and 2015 is estimated to be approximately 201 [25,26].

In the literature, many essential studies exist with regard to shipyard RAs. Barlas [27] appraised the mortal jobrelated accidents in the Turkish shipyards and classified them according to fatality reason, age, etc. Lee et al. [28] introduced a RA for the Korean shipyards concerning design, workforce, raw material supply, and risk number. Buksa et al. [29] assessed risk priority numbers based on the FMEA method and recommended reformative actions to reduce the risk priorities. Moreover, Barlas [30] used the AHP method to detect essential safety measures to prevent accidents in the Turkish shipyards. Occupational accidents, accident types, occurrence dates, and sites were investigated in the Japanese shipyards [27].

Additionally, Seker et al. [26] offered a novel occupational risk-assessment method to formulate appropriate precaution strategies to prevent crucial accidents. A risk-assessment technique for the production processes of large-sized steel ship hulls was developed by [31]. Basuki et al. [32] conducted a RA on the construction of new vessels using the Bayesian network approach so that the RA was conducted using a probabilistic value at risk. Moreover, the evaluation of risks using a statistical approach was studied in [33,34].

It is clear that in a risk-assessment procedure, we can face different uncertainties. By integrating risk-assessment approaches into a fuzzy concept, considering any uncertainty can be possible. Fuzzy sets have achieved great success in handling

inexact and imprecise data in various fields [35,36]. Therefore, this paper attempts to formulate an integrated risk-assessment method by compounding the FineKinney, FAHP, and FVIKOR methods using spherical fuzzy numbers to make the RA more effective. Spherical fuzzy sets (SFSs) introduced by Gündoğdu and Kahraman [37] are one of the most popular extensions of the ordinary fuzzy sets in the literature. Unlike the other extensions of the ordinary fuzzy sets such as intuitionistic, Pythagorean, and q-rung orthopair fuzzy sets, which consider just membership and non-membership degrees, SFSs provide a larger preference domain for evaluators, and each decision maker may also assign the membership, non-membership, and hesitancy levels by satisfying the requirement that the squared sum of these levels must be within the unit sphere [38]. SFSs let decision makers have more flexibility in giving different values for uncertainty degrees (membership, non-membership, and hesitancy degrees). The advantage of these fuzzy sets is used for the first time in shipyard risk-assessment analysis, where the uncertainty is high. Further, a new dimension, i.e., "undetectability," has been added to the risk-assessment analysis.

The rest of the paper is organized as follows: Section 2 briefly introduces the basic preliminaries of the FineKinney method and SFSs. In Section 3, the new riskassessment methodology is presented based on the integration of the spherical FAHP and VIKOR methods. Section 4 presents an application for a case study in the shipyard industry in Turkey. In Section 5, a sensitivity analysis is performed to illustrate the validity of the proposed approach. Finally, the paper is concluded in Section 6 in addition to describing future directions.

\section{Preliminaries and Basic Concepts}

In this section, the basic information and operations of the Fine-Kinney, FMEA, and SFSs will be explained briefly to make the proposed approach more understandable.

\subsection{The Fine-Kinney and FMEA Methods}

The Fine-Kinney method is a quantitative risk appraisal tool utilized to mathematically assess and control accidents and hazards [12]. This method is a technique used to determine the rank of accomplishment of measures based on the order of risks and where to use resources first [18]. The risk value is the product of three parameters $(C, E$, and $P)$, which are introduced as follows [12]:

The severity of consequences for an employee in case of threats or hazards $(C)$ : is the most likely result in a potential accident. These values are graded within the interval of $(1,100)$. A high score means that doubt or instability exists about the severity of the incident.

The exposure frequency of the occurrence of threats and hazards $(E)$ : the frequency of the occurrence of a hazard. These values are graded within the interval of $(0.5,10)$.

The probability of an accident $(P)$ : The likelihood that a hazardous event may occur. These values are sorted within the interval of $(0.1,10)$.

Therefore, the formula of the risk score $(R)$ is denoted as below;

$R=C \times E \times P$. 
The probability, frequency, and severity degrees are multiplied using Equation (Eq). (1) to obtain the risk score. These risk scores are classified as "acceptable risk," "risk," "important risk," "high risk," and "very high risk" [12].

FMEA is used to recognize potential failures and discover what effect the failures would have. Thus, an extra dimension exists, which is "undetectability." The present study also incorporated the FMEA into the Fine-Kinney methods to provide an accurate RA. This work developed the new riskassessment method with SFSs under four risk parameters: probability $(\mathrm{P})$, undetectability $(\mathrm{U})$, consequence $(\mathrm{C})$, and exposure (E).

\subsection{Preliminaries of Spherical Fuzzy Sets}

Single-valued SFSs are defined in Definition 1. SFSs provide a large preference domain for evaluators by satisfying the unit sphere condition as defined in Eq. (3).

Definition 1. A single-valued SFS $\widetilde{A}_{S}$ of the universe of discourse $X$ is given by [37]

$\tilde{A}_{s}=\left\{x, \mu_{\tilde{A}_{s}}(x), \vartheta_{\tilde{A}_{s}}(x), I_{\tilde{A}_{s}}(x) \mid x \in X\right\}$,

where $\mu_{\widetilde{A}_{s}}(u), \vartheta_{\widetilde{A}_{s}}(u)$, and $I_{\widetilde{A}_{s}}(u): U \rightarrow[0,1]$ are the degree of membership, non-membership, and indeterminacy of $x$ to $\widetilde{A}_{S^{\prime}}$ respectively. Moreover,

$$
0 \leq \mu_{\tilde{A}_{s}}^{2}(x)+\vartheta_{\tilde{A}_{s}}^{2}(x)+I_{\tilde{A}_{s}}^{2}(x) \leq 1 .
$$

Then $\sqrt{1-\left[\mu_{\tilde{A}_{s}}^{2}(x)+\vartheta_{\tilde{A}_{s}}^{2}(x)+I_{\tilde{A}_{s}}^{2}(x)\right]}$ is defined as the refusal degree of $x$ in $X$.

Definition 2. Suppose that $\widetilde{A}_{s}$ and $\widetilde{B}_{s}$ are two spherical fuzzy numbers that include the membership, non-membership, and indeterminacy degrees. The basic operations of SFSs can then be defined as follows [37] (formulas between 4-7 are given below):

$$
\begin{aligned}
& \tilde{A}_{s} \oplus \tilde{B}_{s}=\left\{\sqrt{\mu_{\tilde{A}_{s}}^{2}+\mu_{\bar{S}_{s}}^{2}-\mu_{\tilde{A}_{s}}^{2} \mu_{\bar{B}_{s}}^{2}}, \vartheta_{\tilde{A}_{s}} \vartheta_{\tilde{B}_{s^{\prime}}} \sqrt{\left(1-\mu_{\bar{B}_{s}}^{2}\right) L_{\tilde{A}_{s}}^{2}+\left(1-\mu_{\tilde{A}_{s}}^{2}\right) I_{\tilde{B}_{s}}^{2}-I_{\tilde{A}_{s}}^{2} L_{\bar{B}_{s}}}\right\} \\
& \tilde{A}_{s} \otimes \tilde{B}_{s}=\left\{\mu_{\tilde{A}_{s}} \mu_{\tilde{B}_{S^{\prime}}} \sqrt{\vartheta_{\tilde{A}_{s}}^{2}+\vartheta_{\bar{B}_{s}}^{2}-\vartheta_{\tilde{A}_{s}}^{2} \vartheta_{\bar{B}_{s}}^{2}}, \sqrt{\left(1-\vartheta_{\bar{B}_{s}}^{2}\right) I_{\bar{A}_{s}}^{2}+\left(1-\vartheta_{\tilde{A}_{s}}^{2}\right) I_{\bar{B}_{s}}^{2}-I_{\tilde{A}_{s}}^{2} L_{\bar{B}_{s}}^{2}}\right\} \\
& k \tilde{A}_{s}=\left\{\sqrt{1-\left(1-\mu_{\tilde{A}_{s}}^{2}\right)^{k}}, \vartheta_{\tilde{A}_{s^{\prime}}}^{k} \sqrt{\left(1-\mu_{\tilde{A}_{s}}^{2}\right)^{k}-\left(1-\mu_{\bar{A}_{s}}^{2}-I_{\bar{A}_{s}}^{2}\right)^{k}}\right\} ; k>0 \\
& \tilde{A}_{s}^{k}=\left\{\mu_{\tilde{A}_{s^{\prime}}}^{k} \sqrt{1-\left(1-\vartheta_{\tilde{A}_{s}}^{2}\right)^{k}}, \sqrt{\left(1-\vartheta_{\tilde{A}_{s}}^{2}\right)^{k}-\left(1-\vartheta_{\tilde{A}_{s}}^{2}-I_{\tilde{A}_{s}}^{2}\right)^{k}}\right\} ; k>0 .
\end{aligned}
$$

Definition 3. Spherical fuzzy weighted arithmetic mean (SFWAM) with respect to $w=\left(w_{1}, w_{2}, \ldots, w_{n}\right) ; w_{i} \in[0,1]$; $\sum_{i=1}^{n} w_{i}=1$, SFWAM is defined as [37] ( $8^{\text {th }}$ formula is below):

$$
\left\{\begin{array}{l}
\operatorname{SFWAM}_{w}\left(\tilde{A}_{S 1}, \tilde{A}_{S 2}, \ldots, \tilde{A}_{S n}\right)=w_{1} \tilde{A}_{S 1}+w_{2} \tilde{A}_{S_{2}}+\cdots+w_{n} \tilde{A}_{S n}= \\
\left\{\sqrt{1-\prod_{i=1}^{n}\left(1-\mu_{A_{s}}^{2}\right)^{w_{i}}}, \prod_{i=1}^{n} \vartheta_{A_{s}}^{w_{i}}, \sqrt{\prod_{i=1}^{n}\left(1-\mu_{A_{s}}^{2}\right)^{w_{i}}-\prod_{i=1}^{n}\left(1-\mu_{A_{s}}^{2}-I_{A_{s}}^{2}\right)^{w_{i}}}\right\} .
\end{array}\right.
$$

Definition 4. Spherical fuzzy weighted geometric mean (SFWGM) with respect to $w=\left(w_{1}, w_{2}, \ldots, w_{n}\right) ; w_{i} \in[0,1]$; $\sum_{i=1}^{n} w_{i}=1$, SFWGM is defined as [37] ( $9^{\text {th }}$ formula is below):

$$
\begin{aligned}
& \operatorname{SFWGM}_{w}\left(\tilde{A}_{S 1}, \tilde{A}_{S 2}, \ldots, \tilde{A}_{S n}\right)=\tilde{A}_{S S^{\prime}}{ }^{{ }_{1}}+\tilde{A}_{S 2}{ }^{w_{2}}+\cdots+\tilde{A}_{S n}{ }^{{ }^{w}}= \\
& \left\{\prod_{i=1}^{n} \mu_{A_{S}}^{w_{i}}, \sqrt{1-\prod_{i=1}^{n}\left(1-\vartheta_{A_{S}}^{2}\right)^{w_{i}}}, \sqrt{\prod_{i=1}^{n}\left(1-\vartheta_{A_{S}}^{2}\right)^{w_{i}}-\prod_{i=1}^{n}\left(1-\vartheta_{A_{S}}^{2}-I_{A_{S}}^{2}\right)^{w_{i}}}\right\} .
\end{aligned}
$$

\section{The Proposed Spherical Fuzzy Risk- Assessment Methodology}

In the proposed spherical fuzzy (SF)-AHP\&SF-VIKOR methodology, the weights of risk parameters are first calculated using the SF-AHP. These weights are then used in the SF-VIKOR method to find the priorities of hazards. Figure 1 gives the general framework of the proposed methodology.

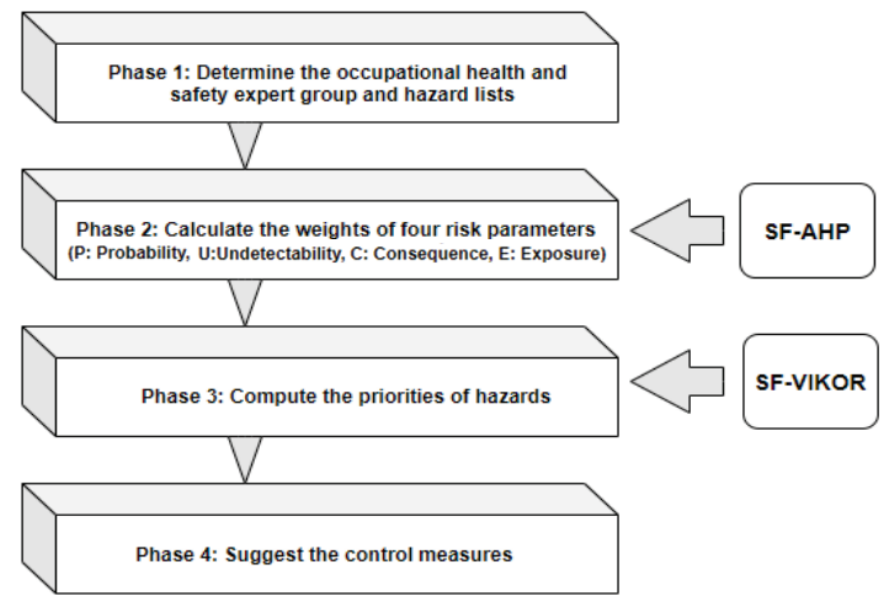

Figure 1. The proposed risk-assessment framework

SF-AHP: Spherical fuzzy analytic hierarchy process, SF-VIKOR: Spherical fuzzy VlseKriterijumska Optimizacija I Kompromisno Resenje

Table 1 indicates linguistic terms to construct pairwise matrices based on SF-AHP and linguistic terms to construct decision matrices based on SF-VIKOR. 
Table 1. Linguistic terms for SF-AHP and SF-VIKOR

\begin{tabular}{|c|c|c|}
\hline SF-AHP linguistic terms & $(\mu, \vartheta, \pi)$ & $\begin{array}{l}\text { SF-VIKOR linguistic } \\
\text { terms }\end{array}$ \\
\hline $\begin{array}{l}\text { Absolutely more } \\
\text { important (AMI) }\end{array}$ & $(0.9,0.1,0.0)$ & Very high (VH) \\
\hline Very high important (VHI) & $(0.8,0.2,0.1)$ & $\operatorname{High}(\mathrm{H})$ \\
\hline High important (HI) & $(0.7,0.3,0.2)$ & Medium high (MH) \\
\hline $\begin{array}{l}\text { Slightly more important } \\
\text { (SMI) }\end{array}$ & $(0.6,0.4,0.3)$ & Slightly high (SH) \\
\hline Equally important (EI) & $(0.5,0.4,0.4)$ & --- \\
\hline $\begin{array}{l}\text { Slightly low important } \\
\text { (SLI) }\end{array}$ & $(0.4,0.6,0.3)$ & Slightly low (SL) \\
\hline Low important (LI) & $(0.3,0.7,0.2)$ & Medium low (ML) \\
\hline Very low important (VLI) & $(0.2,0.8,0.1)$ & Low (L) \\
\hline $\begin{array}{l}\text { Absolutely low important } \\
\text { (ALI) }\end{array}$ & $(0.1,0.9,0.0)$ & Very low (VL) \\
\hline \multicolumn{3}{|c|}{$\begin{array}{l}\text { SF-AHP: Spherical fuzzy analytic hierarchy process, SF-VIKOR: Spherical } \\
\text { fuzzy VlseKriterijumska Optimizacija I Kompromisno Resenje }\end{array}$} \\
\hline
\end{tabular}

The steps of the methodology are described in detail in the pseudo code as follows:

\section{Pseudo Representation of Spherical Fuzzy Safety and Critical Effect analysis}

Input: $n$ : number of evaluation criteria ( $i$ and $j$ are aliases $=1,2, \ldots n$ ), $m$ : number of hazards $(h=1,2, \ldots m), \quad p:$ number of experts $(k=1,2, \ldots p)$, $o$ : number of pairwise comparison matrices $(s=1,2, \ldots o)$

Stage 1: Spherical FAHP

Output: Weights of the risk parameters

begin for $s=1: o$ do:

Step 1.1: Construct the linguistic spherical fuzzy judgment matrices

$\left(\tilde{R}=\left(\tilde{r}_{i j}^{k}\right)_{n \times n}\right) \Longrightarrow$ Based on Table 1

Step 1.2: Convert the linguistic terms into corresponding spherical fuzzy numbers $\Longrightarrow$ Based on Table 1

where $\tilde{R}=\left(\tilde{r}^{k}{ }_{i j}\right)_{n \times n}=\left(\left[\mu_{i j}^{\mathrm{k}}, v_{i j}^{\mathrm{k}}, \pi_{i j}^{\mathrm{k}}\right]\right)_{n \times n}$

for each comparison matrix $\widetilde{R}$ do consistency analysis:

$C R=\frac{C I}{R I}$ where $C I=\frac{\lambda_{\max }}{n-1}$

end for

Step 1.3: Analyze the results of consistency analysis if $C R>0.1$ :

return to Step $\mathbf{1 . 1}$

else:

go Step 1.4

end if
Step 1.4: Aggregate the spherical fuzzy pairwise matrices and obtain spherical fuzzy weights of the risk parameters using the spherical fuzzy weighted geometric mean operator:

$\tilde{r}_{i j}=\left\langle\left[\prod_{k=1}^{p}\left(\mu_{i j}^{k}\right)^{w_{k}}, \sqrt{1-\prod_{k=1}^{p}\left(1-v_{i j}^{k^{2}}\right)^{w_{k}},} \sqrt{\prod_{k=1}^{p}\left(1-v_{i j}^{k^{2}}\right)^{w_{k}}-\prod_{k=1}^{p}\left(1-\mu_{i j}^{k^{2}}-v_{i j}^{k^{2}}\right)^{w_{k}}}\right]\right)$

where weights of experts are $w_{k}>0(k=1,2, \ldots, p)$ and $\sum_{k=1}^{p} w_{k}=1$ and $\left(r_{i j}\right)_{n \times n}=\left(\left[\mu_{i j}, v_{i j}, \pi_{i j}\right]\right)_{n \times n}$

end for

Step 1.5: Defuzzify the weights of the risk parameters to get crisp values

for $j=1: n$ do:

$w_{j}=\sqrt{\left|100 *\left[\left(2 \mu_{i j}-\pi_{i j} / 2\right)^{2}-\left(v_{i j}-\pi_{i j} / 2\right)^{2}\right]\right|}$

for $j=1: n$ do normalization:

$\bar{w}_{j}=\frac{w_{j}}{\sum_{j=1}^{n} w_{j}}$

end for

Stage 2: Spherical fuzzy VIKOR

Output: Obtain the priorities of the hazards

for $k=1: p$ do:

Step 2.1: Input linguistic decision matrices $\left(\widetilde{F}_{s}^{k}\right)_{m \times n}$ by each expert $\Longrightarrow$ Based on Table 1

Step 2.2: Convert these linguistic terms to their corresponding spherical fuzzy numbers (SFN)

where $\tilde{f}_{i j}^{k}==\left(\left[\mu_{i j}^{\mathrm{k}}, v_{i j}^{\mathrm{k}}, \pi_{i j}^{\mathrm{k}}\right]\right)_{m \times n}$

Step 2.3: Aggregate the SFN influence matrices using the spherical fuzzy weighted geometric mean

$\tilde{f}_{i j}=\left[\prod_{k=1}^{p}\left(\mu_{i j}^{k}\right)^{w_{k}}, \sqrt{1-\prod_{k=1}^{p}\left(1-v_{i j}^{k^{2}}\right)^{w_{k}}}, \sqrt{\prod_{k=1}^{p}\left(1-v_{i j}^{k^{2}}\right)^{w_{k}}-\prod_{k=1}^{p}\left(1-\mu_{i j}^{k^{2}}-v_{i j}^{k^{2}}\right)^{w_{k}}}\right]$

where $w_{k}>0(k=1,2, \ldots, p)$ and $\sum_{k=1}^{p} w_{k}=1$

\section{end for}

Step 2.4: Compute the SFN best value $\left(\tilde{f}_{j}^{+}\right)$and worst value $\left(\tilde{f}_{j}^{-}\right)$based on the following equations:

$\tilde{f}_{j}^{+}=\left\{\left(\mid\left(\max _{j} \mu_{i j}\right),\left(\underset{j}{\min v_{i j}}\right),\left(\underset{j}{\min \pi_{i j}}\right)\right]|| i=1,2, \ldots, n\right\}^{T}=\left\{\tilde{f}_{1}^{+}, \tilde{f}_{2}^{+}, \tilde{f}_{n}^{+}\right\}^{T}$

$\tilde{f}_{j}^{-}=\left\{\left|\left[\left(\min _{j} \mu_{i j}\right),\left(\max _{j} v_{i j}\right),\left(\max _{j} \pi_{i j}\right)\right]\right| \mid i=1,2, \ldots, n\right\}^{T}=\left\{\tilde{f}_{1}^{-}, \tilde{f}_{2}^{-}, \tilde{f}_{n}^{-}\right\}^{T}$.

Step 2.5: Calculate $S_{i}$ and $R_{i}$ degrees

for $i=1: m$ do:

2.5.1. Compute $\left(S_{i}\right)$ degree

$S_{i}=\sum_{j=1}^{n} \bar{w}_{j}\left[d\left(\tilde{f}_{j}^{+}, \tilde{f}_{i j}\right) / d\left(\tilde{f}_{j}^{+}, \tilde{f}_{j}^{-}\right)\right]$ 
2.5.2. Compute $\left(R_{i}\right)$ degree

$R_{i}=\max _{j}\left[\bar{w}_{j} d\left(\tilde{f}_{j}^{+}, \tilde{f}_{i j}\right) / d\left(\tilde{f}_{j}^{+}, \tilde{f}_{j}^{-}\right)\right]$

where the Zhang and Xu's distance formula is as follows:

$$
\begin{aligned}
d\left(\tilde{f}_{j}^{+}, \tilde{f}_{i j}\right) & =\left(\left|\mu_{i j}{ }^{2}-\left(\mu_{j}^{+}\right)^{2}\right|+\left|v_{i j}{ }^{2}-\left(v_{j}^{+}\right)^{2}\right|+\left|\pi_{i j}{ }^{2}-\left(\pi_{j}^{+}\right)^{2}\right|\right) \\
d\left(\tilde{f}_{j}^{+}, \tilde{f}_{j}^{-}\right) & =\left(\left|\left(\mu_{j}^{-}\right)^{2}-\left(\mu_{j}^{+}\right)^{2}\right|+\left|\left(v_{j}^{-}\right)^{2}-\left(v_{j}^{+}\right)^{2}\right|+\left|\left(\pi_{j}^{-}\right)^{2}-\left(\pi_{j}^{+}\right)^{2}\right|\right),
\end{aligned}
$$

end for

Step 2.6: Calculate the maximum group utility $\left(Q_{i}\right)$

for $i=1: m$ do:

$Q_{i}=v \frac{\left(S_{i}-S^{*}\right)}{\left(S^{-}-S^{*}\right)}+(1-v) \frac{\left(R_{i}-R^{*}\right)}{\left(R^{-}-R^{*}\right)}$

where $S^{*}=\min _{i} S_{i}, S^{-}=\max _{i} S_{i} R^{*}=\min _{i} R_{i}$, and $R^{-}=\max _{i} R_{i}$ and $v=0.5$

\section{end for}

Step 2.7: Rank the alternatives in a descending order $Q_{i}$ end

\section{Application: Spherical Fuzzy Safety and Critical Effect Analysis for Shipyards}

To show the applicability of the proposed approach, a case study was employed to the ship production in Turkey. Shipbuilding contains three processes: design, materials, and production. Each process has different sections. The design process is the initial process that contains the basic design, key plan, yard plan, production drawing, and documentation sections. The materials process is the intermediate part of the shipbuilding that includes the hull construction, paint materials, hull outfitting, machinery, and outfitting. The last process is production that comprises work preparation, hull construction, leak test, hull outfitting, machinery systems, electrical outfitting, painting, corrosion control, and spare parts. Herein, the hazards and associated risks regarding the hull construction in the ship were analyzed. Four risk parameters, i.e., the P, $\mathrm{U}, \mathrm{C}$, and $\mathrm{E}$ of the hazards were evaluated. To assess eleven different hazard risks and their effects on the safety risk of the observed shipbuilding industry, three decision makers, which are represented as Expert 1, Expert 2, and Expert 3, were used. Table 2 illustrates the hazard list, identifications, and possible effects, and Table 3 presents the linguistic evaluations of the risk parameters. Based on Step 1.4, these evaluations were aggregated as given in Table 3.

Table 4 presents the defuzzified and normalized weights of the main risk parameters that are obtained using Step 1.5. The most essential risk parameter is the probability of hazards' occurrences, which is followed by the exposure of the events parameter.

\begin{tabular}{|c|c|c|}
\hline Hazard ID & Hazard Identification & Possible Risk \\
\hline $\begin{array}{l}\text { Hazard } 1 \\
\text { (H1) }\end{array}$ & Working with hand tools & Cuts, injury \\
\hline $\begin{array}{l}\text { Hazard } 2 \\
(\mathrm{H} 2)\end{array}$ & Material handling lifting & $\begin{array}{l}\text { Joint, injury, } \\
\text { discomfort }\end{array}$ \\
\hline $\begin{array}{l}\text { Hazard } 3 \\
\text { (H3) }\end{array}$ & $\begin{array}{l}\text { Layout of the work environment } \\
\text { (unfixed materials) }\end{array}$ & Wound, injury \\
\hline $\begin{array}{c}\text { Hazard } 4 \\
(\mathrm{H} 4)\end{array}$ & $\begin{array}{l}\text { Rotating or moving parts of the } \\
\text { ships }\end{array}$ & Injury, death \\
\hline $\begin{array}{l}\text { Hazard } 5 \\
\text { (H5) }\end{array}$ & Falling objects & Injury, death \\
\hline $\begin{array}{l}\text { Hazard } 6 \\
\text { (H6) }\end{array}$ & $\begin{array}{l}\text { Unsuitable climatic conditions } \\
\text { (too cold or too hot conditions) }\end{array}$ & Disease, injury \\
\hline $\begin{array}{c}\text { Hazard } 7 \\
\text { (H7) }\end{array}$ & Noisy pollution & $\begin{array}{c}\text { Hearing less, stress, } \\
\text { and panic }\end{array}$ \\
\hline $\begin{array}{l}\text { Hazard } 8 \\
(\mathrm{H} 8)\end{array}$ & $\begin{array}{c}\text { Emergency events } \\
\text { (flood, earthquake, fire, etc.) }\end{array}$ & Injury, death \\
\hline $\begin{array}{c}\text { Hazard } 9 \\
(\mathrm{H} 9)\end{array}$ & Working with lifting tools & Injury, death \\
\hline $\begin{array}{l}\text { Hazard } 10 \\
\quad(\mathrm{H} 10)\end{array}$ & $\begin{array}{c}\text { Exposure to chemical liquid, } \\
\text { dust, and gas } \\
\text { (Painting, acids, etc.) }\end{array}$ & $\begin{array}{l}\text { Cancer, burns, eye } \\
\text { disease, irritation }\end{array}$ \\
\hline $\begin{array}{l}\text { Hazard } 11 \\
\quad(\mathrm{H} 11)\end{array}$ & Falling from the ship & Injury, death \\
\hline
\end{tabular}

Table 2. Hazard identification list in the shipwrights [17]

The decision matrix in Table 5 is obtained using Step 2.3. After performing Step 2.4, the SF best $\left(\tilde{f}_{j}^{+}\right)$and worst $\left(\tilde{f}_{j}^{-}\right)$ values are obtained and presented in Table 6.

Table 7 shows the ranking result based on the descending order of $Q_{i}$ values. The first three critical processes/work units in descending order are the material handling lifting (H2), working with the hand tools (H1), and falling objects (H5). The last critical hazard is the emergency events (H8).

To decrease the worst consequences of the riskiest categories (H2, H1, and H5), some control measures can be suggested. The examination of the shipyards in Turkey revealed that the main issues are the insufficient training period with hand tools, handling process, and importance of the usage of protective materials. The training period must be extended to overcome these issues, such as manual lifting, hand tools, and transportation works. Using the height equipment should be reviewed, and the possible damaged items must be changed. Employees must realize the importance of the usage of appropriate protective eyewear, safety gloves, and helmets during work.

\section{Sensitivity Analysis by Changing the Weights of the Risk Parameters}

A sensitivity analysis is a useful process to test the validity of the method. In this research, a sensitivity analysis was performed on the weights of the risk 
Table 3. Linguistic terms for the risk parameters and aggregation results

\begin{tabular}{|c|c|c|c|c|c|c|c|}
\hline \multirow{2}{*}{$\begin{array}{c}\text { Experts } \\
\text { Expert } 1\end{array}$} & \multicolumn{4}{|c|}{ Risk parameters } & \multicolumn{3}{|c|}{ Aggregation results } \\
\hline & $\mathbf{P}$ & $\mathbf{U}$ & C & $\mathbf{E}$ & $\mu$ & $v$ & $\pi$ \\
\hline $\mathbf{P}$ & EI & HI & AMI & SMI & 0.66 & 0.33 & 0.28 \\
\hline $\mathbf{U}$ & LI & EI & SMI & LI & 0.31 & 0.69 & 0.23 \\
\hline C & ALI & SLI & EI & VLI & 0.33 & 0.66 & 0.25 \\
\hline $\mathbf{E}$ & SLI & $\mathrm{HI}$ & VHI & EI & 0.58 & 0.41 & 0.29 \\
\hline Expert 2 & $\mathbf{P}$ & $\mathbf{U}$ & C & $\mathbf{E}$ & $\mu$ & $v$ & $\pi$ \\
\hline $\mathbf{P}$ & EI & VHI & $\mathrm{HI}$ & SMI & 0.64 & 0.34 & 0.28 \\
\hline $\mathbf{U}$ & VLI & EI & SLI & ALI & 0.25 & 0.75 & 0.20 \\
\hline C & LI & SMI & EI & LI & 0.41 & 0.59 & 0.27 \\
\hline $\mathbf{E}$ & SLI & AMI & $\mathrm{HI}$ & EI & 0.58 & 0.41 & 0.29 \\
\hline Expert 3 & $\mathbf{P}$ & $\mathbf{U}$ & C & $\mathbf{E}$ & $\mu$ & $v$ & $\pi$ \\
\hline $\mathbf{P}$ & EI & $\mathrm{HI}$ & SMI & VHI & 0.64 & 0.34 & 0.28 \\
\hline $\mathbf{U}$ & LI & EI & SLI & SMI & 0.44 & 0.55 & 0.30 \\
\hline C & SLI & SMI & EI & VHI & 0.56 & 0.43 & 0.30 \\
\hline $\mathbf{E}$ & VLI & SLI & VLI & EI & 0.30 & 0.70 & 0.23 \\
\hline
\end{tabular}

Table 4. Weights of the risk parameters based on SF-AHP

\begin{tabular}{|c|c|c|c|c|c|}
\hline $\begin{array}{c}\text { Risk } \\
\text { parameters }\end{array}$ & $\boldsymbol{\mu}$ & $\boldsymbol{v}$ & $\boldsymbol{\pi}$ & $\begin{array}{c}\text { Defuzzified } \\
\text { weights }\end{array}$ & $\begin{array}{c}\text { Normalized } \\
\text { weights }\end{array}$ \\
\hline $\mathrm{P}$ & 0.65 & 0.33 & 0.28 & 11,3554 & 0,446 \\
\hline $\mathrm{U}$ & 0.32 & 0.68 & 0.24 & 1,7795 & 0,070 \\
\hline $\mathrm{C}$ & 0.42 & 0.58 & 0.28 & 5,5122 & 0,216 \\
\hline $\mathrm{E}$ & 0.46 & 0.54 & 0.26 & 6,8266 & 0,268 \\
\hline P: Probability, U: Undetectability, C: Consequence, E: Exposure, SF-AHP: \\
Spherical fuzzy analytic hierarchy process \\
\hline
\end{tabular}

parameters. Different important weights can result in different outcomes. The weights of the risk parameters were changed according to the following weight vector: $w_{j}=[0.25,0.25,0.25,0.25]^{T}$ for $j=P, U, C, E$. As seen in Table 8 , the first and last hazards were the same, whereas the other hazards' ranking changed. This indicates the importance of the first hazard that remains the same for each situation. The first and last hazards were not sensitive to the risk parameters weights, whereas the other alternatives were observed to be sensitive.

This study employed a sensitivity analysis by changing the $v$ value, which combines the $S_{i}$ and $R_{i}$ values to get $Q_{i}$, which is the value for the ranking of the hazards. The results indicated that the similarities in the given decisions existed. Figure 2 shows the slightly similar decisions from the proposed approach that were produced by performing the sensitivity analysis.

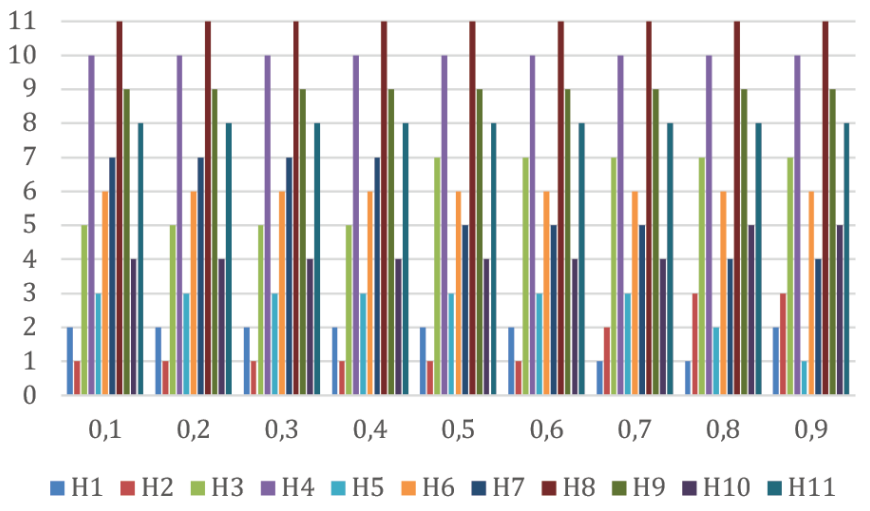

Figure 2. Sensitivity analysis by changing the v value

\section{Conclusion and Future Research Directions}

As in all branches of industry, job-related accidents are a reason for serious social and economic problems owing to physical wounds and deaths. The frequency of fatal accidents in the Turkey's shipyards has forced shipyards to take appropriate actions to improve the safety of the workplace and workforce environment. Therefore, defining, evaluating, and eliminating or reducing risks have become important in reducing fatal and serious occupational injury accidents in shipyards. To this end, the current research presented a hybrid riskassessment approach combining the safety and critical effect analysis (SCEA), AHP, and VIKOR methods. In the proposed framework, the SFSs were used to model the high uncertainty in the risk evaluation process. The SCEA method was employed to determine the main risk 
Table 5. The decision matrix based on the aggregation results of the three experts

\begin{tabular}{|c|c|c|c|c|}
\hline Hazards & Probability (P) & Undetectability (U) & Consequence (C) & Exposure (E) \\
\hline H1 & $(0.83,0.17,0.08)$ & $(0.10,0.90,0.00)$ & $(0.87,0.14,0.06)$ & $(0.66,0.34,0.24)$ \\
\hline H2 & $(0.80,0.20,0.10)$ & $(0.36,0.64,0.27)$ & $(0.80,0.22,0.13)$ & $(0.70,0.31,0.22)$ \\
\hline H3 & $(0.63,0.37,0.27)$ & $(0.40,0.60,0.30)$ & $(0.36,0.66,0.15)$ & $(0.70,0.31,0.22)$ \\
\hline H4 & $(0.16,0.84,0.07)$ & $(0.30,0.70,0.20)$ & $(0.13,0.87,0.05)$ & $(0.90,0.10,0.00)$ \\
\hline H5 & $(0.73,0.29,0.20)$ & $(0.20,0.80,0.10)$ & $(0.77,0.24,0.14)$ & $(0.90,0.10,0.00)$ \\
\hline H6 & $(0.83,0.17,0.08)$ & $(0.70,0.30,0.20)$ & $(0.70,0.30,0.20)$ & $(0.26,0.74,0.17)$ \\
\hline H7 & $(0.90,0.10,0.00)$ & $(0.60,0.40,0.30)$ & $(0.90,0.10,0.00)$ & $(0.16,0.84,0.07)$ \\
\hline H8 & $(0.10,0.90,0.00)$ & $(0.10,0.90,0.00)$ & $(0.20,0.80,0.10)$ & $(0.87,0.14,0.06)$ \\
\hline H9 & $(0.16,0.84,0.07)$ & $(0.16,0.84,0.07)$ & $(0.18,0.82,0.11)$ & $(0.90,0.10,0.00)$ \\
\hline H10 & $(0.73,0.27,0.17)$ & $(0.90,0.10,0.00)$ & $(0.29,0.72,0.16)$ & $(0.77,0.24,0.14)$ \\
\hline H11 & $(0.26,0.74,0.17)$ & $(0.10,0.90,0.00)$ & $(0.20,0.80,0.10)$ & $(0.87,0.14,0.06)$ \\
\hline
\end{tabular}

Table 6. SF best $\left(\tilde{f}_{j}^{+}\right)$and worst $\left(\tilde{f}_{j}^{-}\right)$values

\begin{tabular}{|c|l|l|l|l|}
\hline$\tilde{f}_{j}^{+}$ & $(0.90,0.10,0.00)$ & $(0.90,0.10,0.00)$ & $(0.90,0.10,0.00)$ & $(0.90,0.10,0.00)$ \\
\hline$\tilde{f}_{j}^{-}$ & $(0.10,0.90,0.00)$ & $(0.10,0.90,0.00)$ & $(0.13,0.87,0.00)$ & $(0.16,0.84,0.00)$ \\
\hline \multicolumn{5}{|c|}{ SF: Spherical fuzzy } \\
\hline
\end{tabular}

Table 7. $S_{i} R_{i}$ and $Q_{i}$ values and the ranking results

\begin{tabular}{|c|c|c|c|c|c|c|}
\hline Hazards & $\boldsymbol{S}_{\boldsymbol{i}}$ & Rank & $\boldsymbol{R}_{\boldsymbol{i}}$ & Rank & $\boldsymbol{Q}_{\boldsymbol{i}}$ & Rank \\
\hline H1 & 0.216258 & 2 & 0.095691 & 2 & 0.020533 & 2 \\
\hline H2 & 0.224669 & 3 & 0.083806 & 1 & 0.012297 & 1 \\
\hline H3 & 0.459935 & 7 & 0.170784 & 4 & 0.361278 & 7 \\
\hline H4 & 0.685757 & 10 & 0.414921 & 9 & 0.918169 & 10 \\
\hline H5 & 0.212026 & 1 & 0.109679 & 3 & 0.03574 & 3 \\
\hline H6 & 0.356692 & 6 & 0.235738 & 6 & 0.350584 & 6 \\
\hline H7 & 0.299090 & 4 & 0.268965 & 7 & 0.340456 & 5 \\
\hline H8 & 0.726081 & 11 & 0.445766 & 11 & 1 & 11 \\
\hline H9 & 0.682779 & 9 & 0.414921 & 9 & 0.915272 & 9 \\
\hline H10 & 0.332185 & 5 & 0.176793 & 5 & 0.245322 & 4 \\
\hline H11 & 0.643978 & 8 & 0.363663 & 8 & 0.806727 & 8 \\
\hline
\end{tabular}

parameters. Moreover, the SF-AHP method was utilized to find the weight of the risk parameters, and the SF-VIKOR was then employed to obtain the priority of the hazards. To explain the effectiveness of the proposed approach, a case study was employed to ship production in Turkey. Results showed that in the Turkish shipyard industry, material handling lifting, working with hand tools, and falling objects are major risks. Therefore, employers should consider some preventive control measures to reduce human losses. To demonstrate the validity of the proposed method, a sensitivity analysis was performed
Table 8. Ranking based on the new weights of the risk parameters

\begin{tabular}{|c|c|c|}
\hline Hazards & $\boldsymbol{Q}_{\boldsymbol{i}}$ & Rank \\
\hline H1 & 0.566932 & 7 \\
\hline H2 & 0.019083 & 1 \\
\hline H3 & 0.273350 & 3 \\
\hline H4 & 0.922319 & 9 \\
\hline H5 & 0.307946 & 4 \\
\hline H6 & 0.367310 & 5 \\
\hline H7 & 0.555584 & 6 \\
\hline H8 & 0.993654 & 11 \\
\hline H9 & 0.837595 & 8 \\
\hline H10 & 0.175302 & 10 \\
\hline H11 & 0.940003 & 2 \\
\hline
\end{tabular}

on changing the weight of the risk parameters and $v$ value; the results were sensitive to the weight of the risk parameters. Moreover, the result showed that the new method is robust and flexible in the application.

For future research, the authors recommend the proposed hybrid method by combining fuzzy inference systems to be used in the RA of construction, medical, operational, or other industries, including situations with high uncertainty and risks. Furthermore, some other MCDM approaches such as TOPSIS, ANP, OPA, and their fuzzy versions can be combined with traditional risk-assessment methods. 


\section{Authorship Contributions}

Concept design: F. Kutlu Gündoğdu, S.A. Seyfi-Shishavan, Data Collection or Processing: F. Kutlu Gündoğdu, S.A. SeyfiShishavan, Analysis or Interpretation: F. Kutlu Gündoğdu, S.A. Seyfi-Shishavan, Literature Review: F. Kutlu Gündoğdu, S.A. Seyfi-Shishavan, Writing, Reviewing and Editing: F. Kutlu Gündoğdu, S.A. Seyfi-Shishavan.

Funding: The authors declared that this study received no financial support.

\section{References}

[1] M. Ozkok, "Risk assesment in ship hull structure production using FMEA," Journal of Marine Science and Technology (Taiwan), vol. 22, pp. 173-185, 2014.

[2] A. Pinto, I.L. Nunes, and R.A. Ribeiro, "Occupational risk assessment in construction industry - overview and reflection," Safety Science, vol. 49, pp. 616-624, Jun 2011.

[3] B.O. Alli, Fundamental principles of occupational health and safety. 2nd ed. International Labour Office, 2008.

[4] E. Ilbahar, A. Karaşan, S. Cebi, and C. Kahraman, "A novel approach to risk assessment for occupational health and safety using Pythagorean fuzzy AHP \& fuzzy inference system," Safety Science, vol. 103, pp. 124-136, March 2018.

[5] J.R.C. Nurse, S. Creese and D. De Roure, "Security risk assessment in internet of things systems. arXiv, Oct 2018.

[6] M. Rausand and S. Haugen. Risk Assessment: Theory, Methods, and Applications, 2nd ed. Hoboken, New Jersey: John \& Wiley Sons, 2020

[7] M. Zanko and P. Dawson, "Occupational health and safety management in organizations: a review," International Journal of Management Reviews, vol. 14, pp. 328-344, Aug 2011.

[8] S. Verma and S. Chaudhari, "Highlights from the literature on risk assessment techniques adopted in the mining industry: a review of past contributions, recent developments and future scope," International Journal of Mining Science and Technology, vol. 26, pp. 691-702, Jul 2016.

[9] M. Gul, "Application of pythagorean fuzzy AHP and VIKOR methods in occupational health and safety risk assessment: the case of a gun and rifle barrel external surface oxidation and colouring unit," International Journal of Occupational Safety and Ergonomics, pp. 715-718, Jul 2018.

[10] J. Joy, "Occupational safety risk management in Australian mining." Occupational Medicine, vol. 54 pp. 311-315, Aug 2004.

[11] J. Tang, X. Liu and W. Wang, "A hybrid risk prioritization method based on generalized TODIM and BWM for Fine-Kinney under interval type-2 fuzzy environment," Human and Ecological Risk Assessment, pp. 954-979, Jul 2020.

[12] G.F. Kinney, and A. D. Wiruth, "Practical risk analysis for safety management," Naval Weapons Center, vol. 20, pp. 1-25, Jun 1976.

[13] M. Oturakçı, C. Dağsuyu, and Ali Kokangül, "A new approach to fine kinney method and an implementation study," Alphanumeric Journal, vol. 3, pp. 83-92, Dec 2015.

[14] A. Kokangül, U. Polat and C. Dağsuyu, "A new approximation for risk assessment using the AHP and Fine Kinney methodologies." Safety Science, vol 91, pp. 24-32, Jan 2017.
[15] W. Wang, X. Liu and Y. Qin, Y. "A fuzzy Fine-Kinney-based risk evaluation approach with extended MULTIMOORA method based on Choquet integral," Computers \& Industrial Engineering, vol. 125, pp. 111-123, Nov 2018.

[16] M. Gul and E. Celik, E. "Fuzzy rule-based Fine-Kinney risk assessment approach for rail transportation systems," Human and Ecological Risk Assessment: An International Journal, vol. 24, pp. 1786-1812, Dec 2017.

[17] M. Gul, B. Guven and A.F. Guneri, "A new Fine-Kinney-based risk assessment framework using FAHP-FVIKOR incorporation," Journal of Loss Prevention in the Process Industries, vol. 53, pp. 3-16, May 2018.

[18] F. Yllmaz and M. Ozcan, "A risk analysis and ranking application for lifting vehicles used in construction sites with integrated AHP and fine-kinney approach," Advances in Science and Technology Research Journal, vol. 13, pp. 152-161, Sept 2019.

[19] A. Karasan, E. Ilbahar, S. Cebi and C. Kahraman, "A new risk assessment approach: Safety and Critical Effect Analysis (SCEA) and its extension with Pythagorean fuzzy sets," Safety Science, vol. 108, pp. 173-187, May 2018.

[20] M. Gul, A.F. Guneri and M. Baskan, M. "An occupational risk assessment approach for construction and operation period of wind turbines," Global Journal of Environmental Science and Management, vol. 4, pp. 281-298, Summer 2018.

[21] M. Gul, S. Mete, F. Serin and E. Celik, Fine-kinney-Based Fuzzy Multi-criteria Occupational Risk Assessment, Approaches, Case Studies and Python Applications, Cham: Springer International Publishing, 2021.

[22] M. Gul, S. Mete, F. Serin and E. Celik, Fine-kinney-based occupational risk assessment using fuzzy best and worst method (F-BWM) and Fuzzy MAIRCA, Cham: Springer International Publishing, 2021, pp. 13-30, Sept 2020.

[23] M. Gul, S. Mete, F. Serin and E. Celik, Fine-kinney-based occupational risk assessment using interval type-2 fuzzy QUALIFLEX, Cham: Springer International Publishing, 2021, pp. 135-149, Sept 2020.

[24] A.I. Yilmaz, F. Yilmaz, and U. Celebi, "Analysis of shipyard accidents in Turkey". British Journal of Applied Science \& Technology, vol. 5, pp. 472-481, Nov 2014.

[25] Ö.U. Senturk, "The shipbuilding industry in Viet Nam" OECD Journal: General Papers, 2010, 71-103.

[26] S. Seker, F. Recal and H. Basligil, "A combined DEMATEL and grey system theory approach for analyzing occupational risks: a case study in Turkish shipbuilding industry," Human and Ecological Risk Assessment, vol. 23, pp. 1340-1372, Jul 2017.

[27] B. Barlas, Occupational fatalities in shipyards: an analysis in Turkey. Brodogradnja, vol. 63, pp. 35-41.

[28] E. Lee, Y. Park, J.G. Shin, "Large engineering project risk management using a Bayesian belief network," Expert Systems with Applications, vol. 36, pp. 5880-5887, April 2009.

[29] T. Buksa, D. Pavletic, and M. Sokovic, M. "Shipbuilding pipeline production quality improvement." Journal of Achivements in Materials and Manufacturing Engineering, vol. 40, pp. 160-166, June 2010.

[30] B. Barlas, Shipyard fatalities in Turkey. Safety Science, vol. 50, pp. 1247-1252, Jun 2012. 
[31] R. R. Iwańkowicz and W. Rosochacki, "Clustering risk assessment method for shipbuilding industry," Industrial Management and Data Systems, vol. 114, pp. 1499-1518, Oct 2014.

[32] M. Basuki, D. Manfaat, S. Nugroho and A.A.B. Dinariyana, "Probabilistic risk assessment of the shipyard industry using the bayesian method," International Journal of Technology, vol. 5, pp. 88-97, Dec 2013.

[33] S. Gatti, A. Rigamonti, F. Saita and M. Senati, "Measuring valueat-risk in project finance transactions," European Financial Management, vol. 13, pp. 135-158, Jan 2007.

[34] M. Basuki and S. Widjaja. Studi pengembangan model manajemen rısıko usaha bangunan baru pada ındustrı galangan kapal. Prosiding Seminar Nasional Teknologi Produksi, Jurusan Teknik Perkapalan, 2008.

[35] E, Farrokhizadeh, S. A. Seyfi-Shishavan, Y. Donyatalab and S.H. Seifi, "Interval valued q-rung orthopair fuzzy EDAS method and
Its application to supplier selection," International Conference on Intelligent and Fuzzy Systems, pp. 457-465, Jul 2020.

[36] Y. Donyatalab, E. Farrokhizadeh, S.A. Seyfi-Shishavan, and S.H. Seifi, "Hamacher aggregation operators based on interval-valued q-rung orthopair fuzzy sets and their applications to decision making problems," International Conference on Intelligent and Fuzzy Systems, pp. 466-474, July 2020.

[37] F.K. Gündoğdu and C. Kahraman, "Spherical fuzzy sets and spherical fuzzy TOPSIS method," Journal of Intelligent and Fuzzy Systems, vol. 36, pp. 337-352, Feb 2019.

[38] E. Farrokhizadeh, S.A. Seyfi-Shishavan, F. Kutlu Gündoğdu, Y. Donyatalab, C. Kahraman and S.H. Seifi, "A spherical fuzzy methodology integrating maximizing deviation and TOPSIS methods," Engineering Applications of Artificial Intelligence, vol. 101, pp. 104212, May 2021. 